\title{
PENERAPAN ALGORITMA C4.5 UNTUK PENENTUAN PENERIMA BEASISWA (Studi Kasus: SDN Karawang Kulon III)
}

\author{
${ }^{1}$ Jajam Haerul Jaman, ${ }^{2}$ Novia Indriyani Puji Astuti \\ 1jajam.haeruljaman@unsika.ac.id, 2indriyaninovia27@gmail.com \\ Program Studi Teknik Informatika \\ Fakultas Ilmu Komputer Universitas Singaperbangsa Karawang
}

\begin{abstract}
ABSTRAK
Pendidikan merupakan hal yang sangat penting untuk meningkatkan kualitas seseorang. Memperoleh pendidikan tentunya tidak terlepas dari masalah pendidikan yang kerap dihadapi oleh seseorang yaitu, biaya pendidikan. Maka dari itu pemerintah mengadakan program beasiswa yaitu beasiswa PIP dimaksudkan untuk siswa kurang mampu dan seleksi pemberian beasiswa PIP dilakukan oleh pihak sekolah. penelitian ini memanfaatkan teknik data mining dengan Algoritma C4.5 sebagai prediksi penerima beasiswa di SDN Karawang Kulon III dan kriteria yang digunakan: Pekerjaan orang tua, jumlah penghasilan orangtua, jumlah tanggungan orang tua, jarak tempuh, Penerima KIP, Penerima KPS, nilai rata-rata rapot. Penelitian tanpa fitur seleksi dan menggunakan fitur seleksi Information Gain. Kemudian diaplikasikan menggunakan tools WEKA 3.9.2 dengan Algoritma C4.5. Performa algoritma dilihat dari acuracy, precision, dan error rate, sehingga memberikan nilai performa yang berbeda-beda pada setiap hasilnya. Hasil acuracy, tertinggi precision, dan error rate terendah terdapat pada skenario I dengan 7 kriteria, yaitu nilai acuracy sebesar 93,58\%, nilai precision 95,5\%, dan nilai error rate terendah 6,14\%.
\end{abstract}

Kata Kunci: Beasiswa, Data mining, Algoritma C4.5, information gain, CRISP-DM.

\section{PENDAHULUAN}

Pendidikan merupakan hal yang sangat penting untuk meningkatkan kualitas seseorang. Memperoleh pendidikan tentunya tidak terlepas dari masalah pendidikan yang kerap dihadapi oleh seseorang yaitu, biaya pendidikan. Biaya pendidikan merupakan salah satu faktor yang penting untuk menentukan keberhasilan tujuan pendidikan.

Usaha pemerintah untuk meningkatkan kualitas lulusan siswa salah satunya melalui beasiswa Program Indonesia Pintar (PIP) yang merupakan bantuan berupa uang tunai dari pemerintah yang diberikan kepada peserta didik yang orang tuanya kurang mampu membiayai pendidikannya. Beasiswa PIP dimaksudkan untuk siswa kurang mampu dan kebijakan baru bahwa pada tahun ajaran 2017/2018 seleksi pemberian beasiswa PIP dilakukan oleh pihak sekolah. Hal itu tentu menjadi tugas bagi pihak sekolah untuk melakukan penyeleksian penerima beasiswa agar beasiswa yang diberikan tepat sasaran.

Penelitian ini di lakukan SDN Karawang Kulon III yang sekarang ini mempunyai siswa sebanyak 732 orang yang terbagi dalam 6 kelas. Penelitian ini bertujuam untuk memprediksi penerima beasiswa dengan memanfaatkan teknik data mining, menggunakan algoritma C4.5, sehingga membantu pihak sekolah dalam mencari solusi dan dapat mengetahui tingkat prestasi siswa juga meningkatkan lagi mutu pendidikan sekolah dengan adanya siswa-siswa yang berprestasi.

\section{PENELITIAN SEBELUMNYA}

Klasifikasi rekomendasi beasiswa dilakukan untuk mengklasifikasi apakah siswa akan mendapatkan rekomendasi beasiswa sesuai dengan bobot yang akan di nilai. Klasifikasi dilakukan menggunakan data mining algoritma C4.5. Data yang digunakan yaitu data jurusan, kelas, jumlah nilai, penghasilan orangtua, dan jumlah saudara kandung. Proses data mining pada data training akan menghasilkan pohon keputusan atau rule. Metode evaluasi yang dilakukan dalam penelitian ini yaitu menggunakan confusion matrix dan nilai akurasi, untuk sekali pengujian tingkat akurasi yang dihasilkan yaitu 77\%. hal ini membuktikan bahwa algoritma C4.5 cukup akurat dalam menentukan rekomendasi beasiswa pada SMA Muhammadiyah Gubug. 


\section{METODOLOGI PENELITIAN}

Pada penelitian ini dalam penentuan penerima beasiswa menggunakan algoritma C4.5 menggunkan metode CRIPS-DM.

\section{3.. Dataset}

Penelitian untuk penentuan penerima beasiswa di SDN Karawang Kulon III ditinjau berdasarkan Pekerjaan orang tua, jumlah penghasilan orangtua, jumlah tanggungan orangtua, jarak tempuh, Penerima KIP, Penerima KPS, nilai rata-rata rapot. Kriteria yang dipilih sesuai dengan kombinasi dari berbagai jurnal dan informasi dari pihak Sekolah. Pada tahun ajaran 2017/2018 tercatat jumlah siswa 732 siswa dengan jumlah penerima beasiswa 142 siswa.

\section{Metode}

Pada pemodelan CRIPS-DM, berikut tahapan-tahapannya:

1. Business Understanding (Pemahaman Bisnis)

2. Data Understanding (Pemahaman Data)

3. Data Perparation (Persiapan Data)

4. Modeling (Pemodelan)

5. Evaluation (Evaluasi)

6. Deployment (Penyebaran)

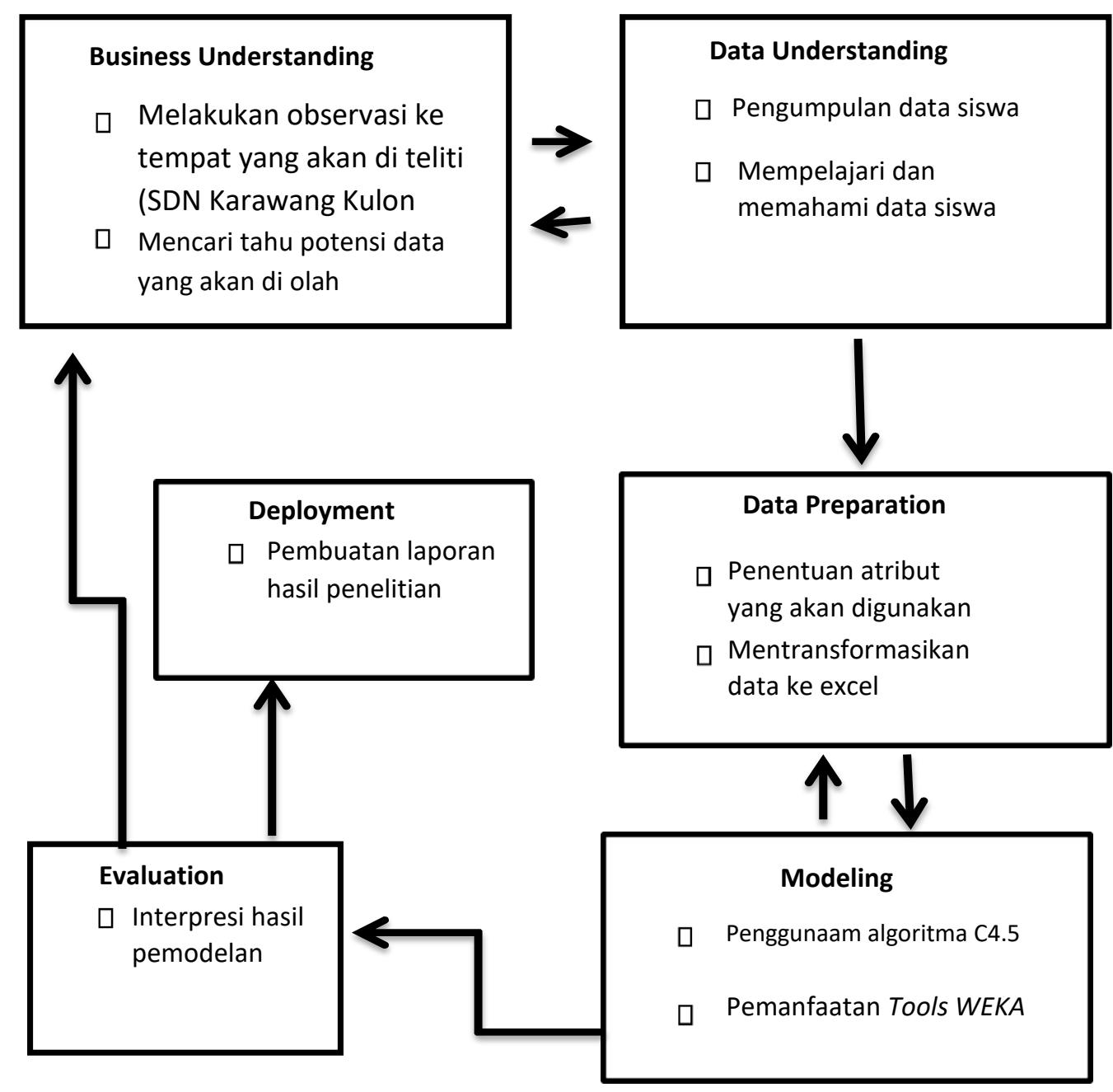




\section{Seleksi Atribut}

Dalam menyelesaikan kasus prediksi penerima beasiswa ini terdapat beberapa data yang diubah dan ditransformasikan ke dalam bentuk lain:

1. Jumlah Penghasilan Orangtua Transformasi dapat dilihat pada gambar 4.2

\begin{tabular}{|l|l|}
\hline Wiraswasta & Rp. $500,000-$ Rp. 999,999 \\
\hline Buruh & 0 - Rp. 500,000 \\
\hline Karyawan Swasta & Rp. $1,000,000-$ Rp. $1,999,999$ \\
\hline Buruh & Rp. 500,000 - Rp. 999,999 \\
\hline Buruh & Rp. 500,000 - Rp. 999,999 \\
\hline PNS/TNI/Polri & Rp. $2,000,000-$ Rp. $4,999,999$ \\
\hline
\end{tabular}

\begin{tabular}{|c|c|c|}
\hline \multirow{6}{*}{ menjadi } & Wiraswasta & 750000 \\
\hline & Buruh & 250000 \\
\hline & Karyawan Swasta & 1500000 \\
\hline & Buruh & 750000 \\
\hline & Buruh & 750000 \\
\hline & PNS/TNI/Polri & 3500000 \\
\hline
\end{tabular}

Gambar 4.1 Transformasi Numerik Jumlah Penghasilan Orang Tua

1. Nilai rata-rata

Dilakukan transformasi dengan mengubah bilangan desimal ke bilangan bulat. Dengan menggunakan fungsi Roundup di Excel Dapat dilihat pada gambar 4.3

\begin{tabular}{|c|c|c|}
\hline \multirow{2}{*}{ RATA-RATA } & \multirow{8}{*}{ menjadi } & Rata-rata \\
\hline & & 81 \\
\hline 80,6 & & 87 \\
\hline 86,5 & & 77 \\
\hline 76,5 & & \\
\hline 82,5 & & 83 \\
\hline 80,5 & & 81 \\
\hline 85,3 & & 86 \\
\hline
\end{tabular}

Gambar 4.2 Perubahan Bilangan Desimal ke Bilangan Bulat

2. Jarak Tempuh

Transformasi data hasil perhitungan Google Maps dapat dilihat pada gambar 4.4

\begin{tabular}{|l|}
\hline \multicolumn{1}{|c|}{ alamat } \\
\hline ANJUN KANOMAN \\
\hline JI. Suriadipati \\
\hline Bunut Kertayasa \\
\hline R. Suriadipati \\
\hline Bunut Kertayasa \\
\hline R. Suriadipati \\
\hline
\end{tabular}

\begin{tabular}{|c|c|}
\cline { 2 - 2 } & jarak tempuh \\
\cline { 2 - 2 } menjadi & $\mathbf{1 6 0 0}$ \\
\cline { 2 - 2 } & $\mathbf{8 0 0}$ \\
\cline { 2 - 2 } & 500 \\
\cline { 2 - 2 } & 800 \\
\hline 500 \\
\hline 800 \\
\hline
\end{tabular}

Gambar 4.3 Transformasi Jarak Tempuh Menggunakan Google Maps

Dari hasil construct data maka didapat dartaset dengan tipe data kategorikal. Dataset dapat dilihat pada tabel 4.7 .

Tabel 4.1 Hasil Construct Data

\begin{tabular}{|c|c|c|c|c|c|c|c|c|}
\hline No & Nama & JTO & nilai & jarak & Pekerjaan & JPO & Penerima KIP & Penerima KPS \\
\hline 1 & AAB ABDUL JABBAR & 1 & 81 & 1600 & buruh & 1500000 & \begin{tabular}{|c|} 
Tidak \\
\end{tabular} & Tidak \\
\hline 2 & Abdul Aziz Muttaqin & 2 & 87 & 800 & Wiraswasta & 1500000 & Үа & Ya \\
\hline 3 & ABDUL FATHIR & 2 & 77 & 500 & Buruh & 1500000 & Tidak & Tidak \\
\hline 4 & ABDUL ROHIM SURYANA & 2 & 83 & 800 & Buruh & 1500000 & Tidak & Tidak \\
\hline 5 & ABI RODIANSAH & 2 & 81 & 500 & Tidak bekerja & 750000 & Ya & $\mathrm{Ya}$ \\
\hline 6 & ABIL SYAHRUL FADHILAH & 1 & 86 & 800 & Buruh & 1500000 & Tidak & Tidak \\
\hline 7 & ADAM TIRADI & 2 & 82 & 500 & Buruh & 750000 & Tidak & Tidak \\
\hline
\end{tabular}




\section{Pengelompokan data}

Dari hasil construct data selanjutnya memproduksi dataset akhir yang siap ditambang ataudiolah dalam tools pemodelan data mining. Format dataset akhir berupa tabel atau query (flat file) untuk pemodelan data mining. Format tabel yang berupa excel akan diganti menjadi format csv agar tabel siap untuk diproses menggunakan Weka. Pada Tabel 4.8 adalah data set akhir.

Tabel 4.2 Dataset Akhir

\begin{tabular}{|l|c|l|}
\hline \multicolumn{1}{|c|}{ Kriteria } & Tipe Data & \multicolumn{1}{c|}{ Keterangan } \\
\hline JTO & Nominal & Merupakan kriteria yang akan diakumulasikan \\
\hline Nilai Rata-rata & Nominal & Merupakan kriteria yang akan diakumulasikan \\
\hline Jarak tempuh & Nominal & Merupakan kriteria yang akan diakumulasikan \\
\hline Pekerjaan orang tua & Nominal & Merupakan kriteria yang akan diakumulasikan \\
\hline JPO & Nominal & Merupakan kriteria yang akan diakumulasikan \\
\hline Penerima KIP & Nominal & Merupakan kriteria yang akan diakumulasikan \\
\hline Penerima KPS & Nominal & Merupakan kriteria yang akan diakumulasikan \\
\hline
\end{tabular}

\section{HASIL DAN PEMBAHASAN}

Hasil yang diperoleh dari keseluruhan tes yang dilakukan baik dengan use training set, dari algoritma $C 4.5$ dapat dilihat pada Tabel di bawah ini: Evaluasi menggunakan Accuracy dan Error Rate dengan pengujian Use Training Set untuk dataset Skenario 1 sampai skenario 6

Tabel 4.Error! No text of specified style in document..3 Accuracy, Error Rate dan Precision Use

Training Set

\begin{tabular}{|c|c|c|c|c|c|}
\hline $\begin{array}{c}\text { Klasifikasi } \\
\text { Algoritma } \\
\text { C4.5 }\end{array}$ & $\begin{array}{c}\text { Data berhasil di } \\
\text { klasifikasikan } \\
1\end{array}$ & $\begin{array}{c}\text { Data gagal di } \\
\text { klasifikasikan }\end{array}$ & $\begin{array}{c}\text { Accuracy } \\
(\%)\end{array}$ & Error Rate (\%) & Precision (\%) \\
\hline $\begin{array}{c}\text { Skenario } \\
1\end{array}$ & 687 & 45 & $93,85 \%$ & $6,14 \%$ & $\begin{array}{c}95,5 \\
\%\end{array}$ \\
\hline $\begin{array}{c}\text { Skenario } \\
2\end{array}$ & 686 & 46 & $93,715 \%$ & $6,28 \%$ & $\begin{array}{c}95,2 \\
\%\end{array}$ \\
\hline $\begin{array}{c}\text { Skenario } \\
3\end{array}$ & 682 & 50 & $93,169 \%$ & $6,83 \%$ & $\begin{array}{c}95,2 \\
\%\end{array}$ \\
\hline $\begin{array}{c}\text { Skenario } \\
4\end{array}$ & 667 & 65 & $91,12 \%$ & $8,879 \%$ & $\begin{array}{c}98,4 \\
\%\end{array}$ \\
\hline $\begin{array}{c}\text { Skenario } \\
5\end{array}$ & 664 & 68 & $90,71 \%$ & $9,28 \%$ & $\begin{array}{c}97,8 \\
\%\end{array}$ \\
\hline $\begin{array}{c}\text { Skenario } \\
6\end{array}$ & 661 & 71 & $90,30 \%$ & $9,699 \%$ & $\begin{array}{c}98,5 \\
\%\end{array}$ \\
\hline
\end{tabular}

Hasil dari Tabel 4.16 klasifikasi pada dataset dengan menggunakan algoritma C4.5 menunjukan bahwa classifier yang terbentuk dengan pengukuran use training set. Terlihat bahwa dengan dataset Skenario 1 menghasilkan tingkat Accuracy sebesar 93,855\% dengan Error rate paling rendah 6,14\% yang artinya bahwa classifier tersebut membentuk model yang baik.

Pada penelitian ini skenario terbaik adalah skenario 1 ( 7 kriteria: Jumlah tanggungan orang tua, nilai rata- rata, jarak tempuh, pekerjaan orang tua, jumlah penghasilan orang tua, penerima KIP dan penerima KPS).

Selain terjadi kestabilan performa pada skenario 1, performa algoritma C4.5 mengalami penurunan. Setelah dianalisi penyebab dari menurunnya performa algoritma C4.5 pada skenario 2 sampai 6 disebabkan oleh atribut yang relevan dengan kelas target dikurangi atau dihilangkan. Hal ini dapat membuktikan bahwa algoritma C4.5 mengalami kendala dalam mendesain pohon keputusan yang optimal. Hasil kualitas keputusan yang 
didapatkan dengan metode pohon keputusan sangat tergantung pada bagaimana pohon tersebut didesain.

\section{KESIMPULAN}

Pengujian Algoritma C4.5 diukur berdasarkan nilai accuracy, precision, dan error rate. Pengujian kinerja menerapkan information gain dengan 7 kriteria yaitu: JTO, nilai, jarak, pekerjaan, JPO, penerima KIP, penerima KPS menghasilkan nilai akurasi sebesar 93,58\%, precision sebesar 95,5\%, error rate 6,14\% dikarenakan memiliki nilai ketepatan prediksi secara benar tertinggi dan persentase dari total data yang diprediksi secara salah terendah. Hasil ini merupakan model terbaik jika dibandingkan dengan skenario yang lain untuk memprediksi penerima beasiswa di SDN Karawang Kulon III karena Semua algoritma klasifikasi berusaha membentuk model yang memiliki akurasi tinggi (Error Rate yang rendah).

\section{DAFTARPUSTKA}

Apriliawan, Y. E. (2015). Teknik Imputasi Missing Values pada Data Mining : Studi Kasus pada Data Hepatitis.SKRIPSI

Fanani, A. Z., \& Maurina, D. (2015). SemarangPenerapan data mining untuk rekomendasi beasiswa pada SMA Muhammadyah Gubug menggunakan algoritma c4.5. Jurnal Informatika , 11(5), $1-5$.

Farida, S. (2017). Penentuan model terbaik pada algoritma navie bayes untuk prediksi penerima beasiswa (Studi kasus : SMA Negri 2 Karawang). SKRIPSI, Karawang.

Guterres, J. A. (2015). Kelayakan algoritma c4.5 sebagai pendukung keputusan dalam pengajuan penerima beasiswa. Jurnal Informtika , A23, 142-147.

Hastuti, N. F. (2013). Pemanfaatan metode k-means clustering dalam penentuan penerima beasiswa. SKRIPSI.

Hijriana, N., \& Muttaqin, R. (2016). Penerapan metode decision tree algoritma c4.5 untuk klasifikasi siswa berprestasi. SKRIPSI.

Meilina, P. (2015). Penerapan data mining dengan metode kalsifikasi menggunakan decision tree dan regresi.

Jurnal Teknologi, 7(1), 12-20.

Muhardi, \& Nisar. (2015). Penentuan penerima beasiswa dengan algoritma fuzzy c-means di universitas megow pak tulang bawang. Jurnal TIM Darmajaya, I(2), 158.

Musthafa, A., Suyono, H., \& Sarosa, M. (2015). Perbandingan kinerja algoritma c.45 dan ahp topsis. Jurnal EECCIS , 9(2), 109-114.

Restuputri , B. A., \& Putri, A. M. (2014). Penentuan kategori beasiswa mahasiswa menggunakan metode fuzzy tsukamoto. SKRIPSI.

Shella, P. (2015). Sistem pendukung keputusan dengan menggunakan decission tree dalam pemberian beasiswa di sekolah menengah pertama (studi kasus di SMP N 2 Rembang). SKRIPSI.

Supriyanti, W., Kusrini, \& Amborowati, A. (2016). perbandingan algoritma c45 dan navie bayes untuk ketepatan pemilihian konsentrasi mahasiswa. Jurnal INFORMA Politeknik Indonusa Surakarta, 1(3), 62-67.

Vulandari, R. T. (2017). Teori dan aplikasi raoiminer. Surakarta: Gava Media. 